\title{
Industrial Structure And Regional Employment Growth
}

\author{
M. H. AtKins and T. W. BuCK*
}

\section{Introduction}

There have been three major lines of approach to regional economic growth theory. The first approach involves the application of an existing body of macroeconomic theory such as neo-classical or Harrod-Domar growth theory to regional economies where space interferes with adjustment mechanisms. The second approach, as exemplified by Richardson ${ }^{1}$, develops a model which explains regional growth in terms of the generation of various types of scale economy, resource immobility and the diffusion of technical progress over space. Each of these approaches can each be described as aggregative since it usually involves a oneproduct assumption or the most rudimentary sectoral disaggregation. The third approach isolates existing regional industrial structure as the critical independent variable in the determination of regional growth and emphasises the regional implications of resource immobility between industries rather than the spatial immobility of resources as such.

This paper makes explicit the theory of regional growth which underpins the whole structural approach to regional analysis. It then briefly reviews certain well-known difficulties involved with the most popular variation of this approach, namely shift-share analysis. Despite the wide recognition of these difficulties and the low-powered nature of the statistical tests performed on the technique's ability, shift-share applications are extremey pervasive. The analysis of variance is proposed as an alternative to shift-share in order to expose the structural approach to extensive empirical testing which may lead ultimately to its justification or refutation.

\section{Shift-Share Analysis}

The theoretical basis of shift-share and associated structural analyses is rarely made explicit. Indeed most practitioners would insist that the technique does not constitute a theory at all, but is rather a mechanical arithmetic operation applied as a standardisation process on raw employment data in preparation for more scientific analysis. It seems clear from recent applications however, that the technique has been asked to perform the functions of a theory. For example, shiftshare has been applied to the explanation of regional growth patterns ${ }^{2}$, to the diagnosis of regional problems ${ }^{3}$, to the design of regional policies ${ }^{4}$, to the appraisal

*Department of Industrial Economics, The University of Nottingham, University Park, Nottingham NG7 $2 \mathrm{RD}$, England. 
of the performance of regional policies ${ }^{5}$, and to regional employment forecasting, which is of immediate concern to this paper.

The sectoral disaggregation which is at the heart of shift-share and related techniques is presumably based upon the notion that the immobility of resources between industries is more important to regional economies than the frictions of space. Different theories of the firm would suggest a number of circumstances in which firms will grow, in employment terms, where they are presently located, and hence a region's existing industrial structure will be a significant determinant of regional employment growth. For example profit maximising firms will locate additional capacity at existing plants if access to inputs and markets or significant scale economies render them maximum profit locations. Alternatively the adoption of a behavioural theory of the firm would also predict locational inertia, where firms are seen as coalitions of interests which may be disrupted by inter-regional industrial movement. In any of these circumstances firms and industries will tend to grow where they are presently located. Different industries are assumed to have their own product and factor markets and resources are not freely interchangeable between them, so the rate of growth of a regional industry now depends largely upon demand and supply considerations as they affect the equivalent industry in the aggregate. Regional employment growth over all industries will to some extent be determined by the existing regional industrial structure, which may owe its existence to the chance location of entrepreneurs in the past, and to transport cost considerations for inputs and sales and other aspects of comparative advantage which may be no longer relevant.

Shift-share analysis purports to identify that part of the difference $\left(\mathrm{g}_{\mathrm{r}}-\mathrm{g}_{\mathrm{n}}\right)$ between the rate of regional employment growth $\left(\mathrm{g}_{\mathrm{r}}\right)$ and the national rate which is attributable to that region's unique industrial structure compared with a reference region, usually the nation. The calculation of this element, known as the industry-mix, composition or structural component, is a routine and welldocumented process, although there is some dispute about the weights which are appropriate. Another component known as the regional-share, competitive or differential component can be obtained as a residual after substracting the composition component from $\left(\mathrm{g}_{\mathrm{r}}-\mathrm{g}_{\mathrm{n}}\right)$, if mixed weights are used ${ }^{6}$, and shows the proportion of regional growth attributable to supposedly equivalent industries growing at different rates nationally and regionally. Thus, shift-share analysis is intended to identify the contribution of a region's industrial structure or mix component, to $\left(\mathrm{g}_{\mathrm{r}}-\mathrm{g}_{\mathrm{n}}\right)$ and the contribution of a competitive component, which is interpreted as indicating the existence of some regional comparative advantage available to regional industries, presumably reflecting transport cost considerations, regional differences in factor quality, the presence of natural resources or the effects of government intervention.

The limitations of shift-share require little explanation. The selection of timeperiods and regions influences the results and inconsistent weights are necessary if $\left(g_{r}-g_{n}\right)$ is to be exhausted by the two components. More importantly, the level of sectoral disaggregation is crucial. A relatively fine system of industrial disaggregation will increase the apparent contribution of the mix component vis- 
a-vis the competitive component. Conceptually however, there is no "ideal" standard industrial classification (SIC). Even if homogeneous products were identifiable, the performance of one regional industry will always have an income and input multiplier effect on other industries. To this extent the regional competitive component may not reflect simply regional comparative advantage or the local growth environment, but will also comprise spurious differential growth which can follow from unidentified mix effects as a result of the application of a coarse SIC or of the indirect implications of industrial structure. It is generally concluded that the industry-mix component provides only a minimum estimate of the contribution of industrial structures to regional growth differences. In addition there can be no statistical significance attributed to the two shift-share components without recourse to time-series analysis, i.e. the laborious application of the shift-share technique to successive periods, observing the stability or otherwise of the components measured. ${ }^{7}$

Despite these shortcomings, shift-share has been proposed as a regional employment forecasting device ${ }^{8}$ in addition to its other extensive applications noted above. Empirical tests of the technique's validity in this context have been performed either on the stability of the competitive component ${ }^{9}$ or on the accuracy of recursive forecasts ${ }^{10}$, with conflicting results. Tests of the first kind have been typically fairly low-powered, consisting of either tests on the independence of the signs of the component in successive time periods or of tests on the significance of correlations between components for regions in different periods. The second, more pragmatic set of tests, relating to the technique's ability to forecast regional employment growth accurately, also provide conflicting results and are subject to the usual criticism that prediction without understanding is dangerous. The apparent success of an inductive devise ex post facto is no guarantee of future performance.

We submit that the point-estimate employment forecasts derived from shiftshare analysis are unreliable given the potentially spurious nature and instability of the components measured. The competitive component from shift-share represents a net outcome for a region, consisting of some regional industries which have grown faster than their national equivalents and some which have grown slower. It does not indicate a consistent "fertility of the soil" in a region in the context of employment cultivation, i.e. it does not measure the region-specific tendency for all regional industries to diverge from their national growth rates by a certain degree. Similarly the regional mix component nets out the regional over- and underrepresentation of nationally growing and declining industries. It is suggested here that any attempt to refute or justify the structural approach to regional growth theory and forecasting should be based upon examination of the crosssectional stability of the structural and competitive effects using the analysis of variance in place of tests on time-series observations on the shift-share components.

\section{Analysis of Variance (ANOVA)}

This technique was introduced in relation to regional problems by Weeden (op.cit) and has the major advantage that tests of statistical significance may 
be performed on the components within one period, thus eliminating the need for the application of shift-share analysis to successive periods.

In this context, the technique consists of the standard multiple regression approach, explaining the employment growth rate $\left(\mathrm{g}_{\mathrm{ir}}\right)$ of each industry $\mathrm{i}$ in region $\mathrm{r}$ as a function of industrial and regional parameters. Thus, the estimating equation is

$$
\mathrm{g}_{\mathrm{ir}}=\mathrm{a}_{\mathrm{i}} \mathrm{D}_{\mathrm{i}}+\mathrm{b}_{\mathrm{r}} \mathrm{D}_{\mathrm{r}}+\mathrm{u}_{\mathrm{ir}}
$$

where $a_{i}$ and $b_{r}$ are the parameters to be estimated and the $D_{i}$ and $D_{r}$ are zero-one dummies for each industry and region. However, the rapid rates of employment growth (and decline) in small regional industries introduces a heteroskedastic disturbance and this requires the-estimation instead of

$$
\mathrm{g}_{\mathrm{ir}} \quad \mathrm{w}_{\mathrm{ir}}=\mathrm{a}_{\mathrm{i}} \mathrm{D}_{\mathrm{i}} \mathrm{w}_{\mathrm{ir}}+\mathrm{b}_{\mathrm{r}} \mathrm{D}_{\mathrm{r}} \mathrm{w}_{\mathrm{ir}}+\mathrm{u}_{\mathrm{ir}} \mathrm{w}_{\mathrm{ir}}
$$

where $\mathrm{w}_{\text {ir }}$ is the base year employment weight of industry $\mathrm{i}$ in region $\mathrm{r}$. Finally, components analogous to the mix and competitive components of shift-share are obtained from linear combinations of the estimates of $a_{i}$ and $b_{r}$ from equation (2). ANOVA composition components which correspond to the mix components of shift-share, are calculated for each region as

$$
\sum_{i}\left(w_{i, z}-w_{i-}\right) a_{i}
$$

where $\mathrm{w}_{\mathrm{i}}$ is the base-year employment weight of industry $\mathrm{i}$ in total national employment. Similarly ANOVA growth components, which are related to shiftshare competitive components but show charactęristics to grow systematically more quickly or slowly in a region than nationally, are obtained for region $r$ from

$$
\mathrm{b}_{\mathrm{r}}-\underset{\mathrm{r}}{\Sigma} \mathrm{w}_{\mathrm{r}} \mathrm{b}_{\mathrm{r}}
$$

where $\mathrm{w}_{\mathrm{r}}$ is the base year employment weight of region $\mathrm{r}$ in the nation.

The value of this suggested replacement for shift-share is that statistical significance can be attributed to the two components ${ }^{11}$, and also in the application of consistent weights. The ANOVA composition component shows the tendency for a region to possess an industrial structure which is consistently advantageous (or disadvantageous) in terms of growth characteristics at the national level of the industries represented. Finally, and importantly in the context of employment forecasting the ANOVA growth component indicates the regionspecific tendency for all regional industries to diverge from their national growth rates by a similar degree.

Table 1 records for illustrative purposes only the application of ANOVA to British regional employment growth. Employment growth in three sub-periods approximating to trade cycles between 1959 and 1971 was analysed for eight 


\section{TABLE 1}

Regional Composition and Growth Components

(percentage changes over four years)

Regional less

National Growth

\begin{tabular}{lcccc} 
Region & $\begin{array}{c}\text { Rates } \\
(1)\end{array}$ & $\begin{array}{c}\text { Composition } \\
(2)\end{array}$ & $\begin{array}{c}\text { Growth } \\
(3)\end{array}$ & $\begin{array}{c}\text { Residual Error } \\
(4)\end{array}$ \\
\hline London \& S E & & & & \\
$59-63$ & -0.49 & $3.49^{* *}$ & $-4.36^{* *}$ & -0.38 \\
$63-67$ & -8.58 & $2.25^{* *}$ & $-6.40^{* *}$ & 4.43 \\
$67-71$ & -4.93 & 1.17 & -1.91 & 4.19
\end{tabular}

\section{Eastern and Southern}

$\begin{array}{rrrrr}59-63 & 8.93 & 2.25^{* *} & 12.48^{* *} & 5.80 \\ 63-67 & 9.90 & 1.37^{*} & 9.37^{* *} & 0.84 \\ 67-71 & 6.40 & 2.11^{* *} & 5.95^{* *} & 1.66\end{array}$

Midlands and Yorks

$\begin{array}{rrrrr}59-63 & 1.62 & 0.26 & 2.86^{*} & 1.50 \\ 63-67 & 0.78 & -0.44 & -2.53^{*} & -3.75 \\ 67-71 & -0.18 & -1.18^{*} & -2.46 & -3.46\end{array}$

South West

$\begin{array}{rrrrr}59-63 & 1.57 & -1.71^{*} & 0.61 & -2.67 \\ 63-67 & 3.44 & -2.58^{* *} & 3.53^{*} & -2.49 \\ 67-71 & 5.68 & 1.00 & 9.60^{* *} & 4.92\end{array}$

North West

$\begin{array}{rrrrr}59-63 & -3.31 & -2.75^{* *} & -5.06^{* *} & -4.50 \\ 63-67 & -0.89 & -1.76^{*} & 3.72^{*} & 2.85 \\ 67-71 & -1.92 & -0.23 & 1.30 & 2.99\end{array}$

North

$\begin{array}{lrccc}59-63 & -7.80 & -4.29^{* *} & -11.27^{* *} & -7.76 \\ 63-67 & 3.82 & 0.59 & 0.07 & -3.16 \\ 67-71 & 4.28 & 1.13 & -0.63 & -3.78\end{array}$

\section{Scotland}

\begin{tabular}{lrrrr}
$59-63$ & -6.40 & $-3.31^{* *}$ & -2.30 & 0.79 \\
$63-67$ & 2.03 & -0.89 & 3.33 & 0.41 \\
$67-71$ & -3.14 & -1.10 & -3.22 & -1.18 \\
\hline Wales & & & & \\
$59-63$ & 3.59 & $-1.53^{*}$ & $4.74^{* *}$ & -0.38 \\
$63-67$ & 4.02 & --0.59 & $-2.86^{*}$ & -7.47 \\
$67-71$ & 7.13 & 0.65 & -1.09 & -7.57 \\
\hline
\end{tabular}


regions, for ninety-four manufacturing industries which approximate the three digit level of the SIC in the United States.

It can be seen from Table 1 that many of the components, especially in later time periods, are insignificant and that the unexplained residuals are substantial. Indeed, nine of the twenty-four growth components are insignificant even at the $5 \%$ level and this result alone would support Brown's earlier finding with regard to the instability of the shift-share competitive component in the United States. It may be concluded from Table 1 that the large residual errors indicate that the structural approach to regional growth does not offer results which are useful in the generation of regional employment forecasts; it may even be felt that the entire structural approach should be abandoned.

Certainly it has to be concluded that structural growth theory in the British context has little to offer the regional forecaster and that excessive reliance has been placed on shift-share, which conceals a host of compensating and unpredictable variations. Nevertheless, we feel that for two reasons a final judgment on the validity of the structural approach should await the application of ANOVA to regional employment growth in the United States. First, regional policies have not been pursued in the United States with anything approaching the vigor of British interventions. (In fact the results in Table 1 are part of a broader study intended to appraise the consequences of regional interventions.) Clearly, the growth components in Table 1, and perhaps also the composition components to some degree, have been modified by a regional policy which has awarded development area status to almost the whole of Scotland, Wales and the North and parts of the North West and South West. Second, Britain is a compact and relatively homogeneous country unlikely to generate the differences in regional levels of overall competitiveness which could be expected within the United States, where regions show distinctive resource endowments, factors of production may vary in quality and distance-costs are higher, making access to markets and inputs more important determinants of regional employment growth.

\section{Conclusions}

Despite the protestations of its practitioners it is now clear that the shiftshare technique does imply a theory of regional growth. The technique has been asked to perform all the standard tasks of theory and it is even doubtful whether a technique can be a mechanical, "descriptive" device without implying causative relationships. The unpretentious award of "descriptive tool only" status to the technique has involved discouragement of the objective testing which has been the fate of other theories. Indeed it is only possible to apply low-powered tests to the technique at all. ANOVA has been suggested as a more satisfactory technique

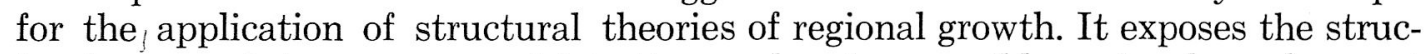
tural approach to more powerful testing and makes possible regional employment forecasts which do not have the rather spurious accuracy of shift-share projections. If subsequent empirical testing refutes the structural approach altogether it may be necessary to conclude that we should resort to the more naive regional forecasting devices suggested by Brown (op. cit) in preference to the apparent sophistry 


\section{of the structural approach. The dangers of forecasting without understanding will then be made explicit.}

\section{FOOTNOTES}

1H. W. Richardson, Regional Growth Theory, Macmillan, London 1973.

2See for example J. R. Lasuen, "Venezuela: An Industrial Shift-Share Analysis 1941 - 61," Regional and Urban Economics, Volume 1, 1971; D. E. Jones, and P. B. Miller, "Regional Growth and Industrial Change in Ohio: A Shift-Share Analysis," Bulletin of Business Research, Volume 48, 1973; and C. C. Paraskevopoulos, "Regional Growth Patterns in Canadian Manufacturing Industry: An Application of Shift and Share Analysis," Canadian Journal of Economics, Volume 7, 1974.

3F. J. B. Stilwell, "Location of Industry and Business Efficiency," Business Ratios, 1968.

${ }_{4}^{4}$ J. A. Kuehn and L. D. Bender, "An Empirical Identification of Growth Centres," Land Economics, Volume 45, 1969.

${ }^{5} \mathrm{~A}$ minor variation of shift-share is used by B. Moore and J. Rhodes, "Evaluating the Effects of British Regional Economic Policy," Economic Journal, Volume 83, 1973.

${ }^{6}$ The calculation of composition and competitive components with consistent (regional or national) weights does not exhaust $(\mathrm{g}-\mathrm{g})$. The use of conflicting weights for the competitive and national weights for the composition component or vice versa, does eliminate any residual, however. See $\mathrm{R}$. Weeden, Regional Rates of Growth of Employment: An Analysis of Variance Treatment, Cambridge University Press, 1974.

7E. Miller, "Employment Projections within a Shift-Share Framework," Review of Regional Studies, Vol. 4, No. 3.

sSee for example C. C. Paraskevopoulos, "Patterns of Regional Economic Growth," Regional and Urban Economics, Volume 4, 1974, especially Appendix A.

${ }_{9}^{9 H}$. J. Brown, "Shift and Share Projections of Regional Economic Growth: An Empirical Test," Journal of Regional Science, Volume 9, 1969; C. C. Paraskevopoulos, "The Stability of the Regional Share Component: An Empirical Test," Journal of Regional Science, Volume 11, 1971; C. F. Floyd and C. F. Sirmans, "Shift and Share Projections Revisited," Journal of Regional Science, Volume 13, 1973; C. C. Paraskevopoulos, "Patterns of Regional Economic Growth," Regional and Urban Economics, Volume 4, 1974.

10H. J. Brown, op cit.; C. F. Floyd and C. F. Sirmans, op cit.

${ }_{11}$ As an alternative, increases (decreases) in absolute numbers employed in industry $i$ in region $r$ could be used.

12See J. Johnston, Econometric Methods, McGraw-Hill, New York, 1972, page 126 et seq. 